\title{
Challenges for the 'Rep' Body
}

At the end of January this year a new Representative Body of the British Dental Association met for the first time in the new triennium. This group, normally referred to as the 'Rep Body', has only been in existence for 3 years following the major restructure of the BDA in 2000. Before then the group was called the Representative Board, and although in appearance the 'Body' may seem similar to its precursor the 'Board', the reality is that the new Body has a different function (as detailed in my editorial at the time1).

The major function of the Body is to set BDA policy and provide strategic direction for the Association for the foreseeable future. This is no small task, as the new Body faces perhaps the most significant period ever in dentistry. Change has not only swept across us (as with all other professions) but change is not necessarily going to be easy for the dental profession to master.

The decisions taken by this Body will affect the lives of all practising dentists in the next decade, as will the reactions to those decisions by other organisations involved in our profession and healthcare in general. We face uncertain times, and the Body needs a group of people ready to take up the challenges and the responsibilities that steering the BDA through this period requires.

Despite the importance of the Rep Body for the profession there are still many dentists for whom the workings of the BDA remain a mystery, and perhaps as a result of this the relevance and importance of the Rep Body and its members is not always appreciated. Quite simply, the Body consists of elected BDA members, dentists who are elected to 'represent' the dental profession in all matters concerning the profession. Hence the name.

But what exactly does the Body do? It is responsible for the governance and policies that the profession decides for itself. These are decided in the three meetings held each year, and refined and honed by the various committees and groups who operate on behalf of the Body throughout the year. The most important of these is the Executive Board composed of members elected from the Body itself plus various other elected representatives from all branches of the profession.

None of the above gives any sense of what actually happens at a Rep Body meeting, and I suspect the experience of attending a first meeting is an 'eyeopener' for many first-time members. It certainly was for me when I attended my first meeting 11 years ago immediately after my appointment as editor. The essence of the experience of a Body meeting can be summed up in a single word - debate. The Body considers current matters and then engages in debate as to how to proceed before making decisions.

So are the Body members up to the challenges ahead? After all, there is a lot going on at the moment. They will need to balance the new Health Bill, Options For Change and the potential ramifications of the role of Primary Care Trusts with uncertainties about the workforce, a growing private market and the registration of PCDs. They must also take into account the pressures on the profession's ability to continue with self-regulation, the changing demographics of the profession itself and the future health needs of the population. As well as all this they need to consider the increasing concerns of the consumer society, the growth of Bodies Corporate and the changes in dental education that are developing throughout all stages of lifelong learning. Of course all of this is taking place in the international environment worldwide. Heady stuff indeed.

At the meeting in January there was a sense that this next triennium was going to require serious work from the Body, and also a sense they were up to it. It is always easy to be wise after the event, but this time I am going to stick my neck out and predict that some of those involved in this Rep Body will go down in history as people who changed the course of dentistry.

\section{Mike Grace m.grace@bda-dentistry.org.uk}

1. Grace M. A new BDA structure. BrDent J 2000; 188: 117 